\title{
Waste glass from end-of-life fluorescent lamps as raw material in geopolymers
}

\author{
Rui M. Novais*, G. Ascensão, M.P. Seabra, J.A. Labrincha \\ Department of Materials and Ceramic Engineering/CICECO - Aveiro Institute of Materials, University of Aveiro, Campus Universitário de Santiago, 3810-193 Aveiro, Portugal
}

\section{A R T I C L E I N F O}

\section{Article history:}

Received 11 January 2016

Revised 18 March 2016

Accepted 3 April 2016

Available online 8 April 2016

\section{Keywords:}

Geopolymers

Fluorescent lamp waste glass

Mechanical properties

Porosity

\begin{abstract}
A B S T R A C T
Nowadays the stunning volume of generated wastes, the exhaustion of raw materials, and the disturbing greenhouse gases emission levels show that a paradigm shift is mandatory. In this context, the possibility of using wastes instead of virgin raw materials can mitigate the environmental problems related to wastes, while reducing the consumption of the Earth's natural resources. This innovative work reports the incorporation of unexplored waste glass coming from end of life fluorescent lamps into geopolymers.

The influence of the waste glass incorporation level, $\mathrm{NaOH}$ molarity and curing conditions on the microstructure, physical and mechanical properties of the geopolymers was evaluated. Results demon strate that curing conditions are the most influential factor on the geopolymer characteristics, while the $\mathrm{NaOH}$ molarity is less important. Geopolymers containing $37.5 \%$ (wt) waste glass were successfully produced, showing compressive strength of $14 \mathrm{MPa}$ (after 28 days of curing), suggesting the possibility of their use in non structural applications.
\end{abstract}

Porous waste based geopolymers for novel applications were also fabricated.

(c) 2016 Elsevier Ltd. All rights reserved.

\section{Introduction}

Climate changes and global warming are probably the most important environmental concerns of the millennium, and are con nected with the distressing increase in the emission of greenhouse gases. The production of cement is one of the main sources of $\mathrm{CO}_{2}$ emissions, due to the decomposition of calcium carbonate (Benhelal et al., 2012), alongside the combustion of fossil fuels. For every ton of cement produced, around 0.85 ton of $\mathrm{CO}_{2}$ are emit ted (Ke et al., 2015) which accounts for $57 \%$ of the total $\mathrm{CO}_{2}$ anthropogenic emissions (Chen et al., 2010). These data show the need to find more sustainable materials that can mitigate these $\mathrm{CO}_{2}$ emissions, and hence contribute to the European Commission directives imposing significant emissions abatement by 2030 (Torres Carrasco and Puertas, 2015). Geopolymers emerge as an excellent alternative to Portland cement (Kajaste and Hurme, 2016; McLellan et al., 2011), not only due to their distinct proper ties, but also owing to their environmental benefits ( $\sim$ six times lower $\mathrm{CO}_{2}$ emissions) (Santa et al., 2013). These materials can be manufactured by alkali activation of aluminosilicate rich materi als at relatively low temperatures (Komnitsas and Zaharaki, 2007). The geopolymer structure encompasses $\mathrm{SiO}_{4}$ and $\mathrm{AlO}_{4}$

\footnotetext{
* Corresponding author.

E-mail address: ruimnovais@ua.pt (R.M. Novais).
}

tetrahedral units, linked alternately by shared oxygen atoms. Alu minosilicate materials such as metakaolin (MK), fly ash and blast furnace slag are commonly used, possibly due to their great abun dance and high content of silica and alumina. Nevertheless, other sources, including several waste streams (e.g. glass), can be utilized provided that highly amorphous silica and/or alumina are present. Indeed, the distressing forecasts regarding global waste production volumes make waste recycling and sustainable use of resources top European priorities. In this context, the possibility of using unex plored wastes as partial replacement of MK would be a positive contribution toward waste management, while reducing the car bon footprint associated with MK.

Waste glass recycling in pavement applications has been previ ously demonstrated (Arulrajah et al., 2014; Imteaz et al., 2012). However these Si rich materials can also be considered as precur sors for the production of geopolymers, even if few investigations on such uses have been conducted to date (Bobirică et al., 2015; Puertas and Torres Carrasco, 2014). Nonetheless, glasses coming from different waste streams (e.g. solar panel glass, glass cullets, TFT LCD glass) have been evaluated (Cyr et al., 2012; Hao et al., 2013; Lin et al., 2012).

Wastes from Electric and Electronic Equipment (e waste) are one of the priority waste streams of EU policy, with an estimated growth of 3 5\%/year (Cucchiella et al., 2015). End of life fluores cent lamps belong to this e waste category, and the worldwide 
annual production is projected to be of the order of 1.5 billion units (Wagner, 2011). According to EU policies, this is a hazardous waste which must be collected and sent to recycling facilities, where it is treated and sorted into several streams. Even though the recovery of valuable materials contained in the lamps (e.g. mercury and rare earths) (Innocenzi et al., 2013; Jang et al., 2005) is already in place, other waste streams, such as waste glass (WG), still require new disposal methods. Glass corresponds to $95 \%$ of the total weight of end of life fluorescent lamps (Lee et al., 2015). Its recycling into new glass products is the main recycling route, yet usually the col lected glass is heavily contaminated with dangerous substances such as $\mathrm{Hg}$ or other lamp components, hindering its re use. This underscores the need for innovative recycling methodologies where their high contamination level is less relevant. Fluorescent lamp WG remains an unexplored waste, and studies considering its potential as a silicate source are rare. Recently, Bobirică et al. (2015) investigated the influence of WG on fly ash and fly ash/blast furnace slag mixtures. The authors observed a decrease in mechan ical strength as the amount of WG increased, which was attributed to the increase on the overall $\mathrm{SiO}_{2} / \mathrm{Al}_{2} \mathrm{O}_{3}$ ratio. Nevertheless, fur ther investigations would shed light on the influencing parameters affecting WG containing geopolymers in order to maximize the potential of this waste material.

There is a fluorescent lamp recycling facility in Portugal produc ing 400 ton/year of contaminated WG, which is currently disposed off in landfills at significant environmental and economic costs. In this work, the feasibility of using fluorescent WG contaminated with metallic and plastic components to form sustainable binders was evaluated. Silica rich WGs ( $71 \%$ (wt)) were used, without any treatment, as a partial replacement of MK. The influence of WG incorporation, $\mathrm{NaOH}$ molarity and curing conditions on the microstructure, physical and mechanical properties of the pro duced geopolymers was evaluated.

Investigations concerning the mechanical properties of geopolymers have been extensively considered (Pelisser et al., 2013; Tzanakos et al., 2014), yet studies regarding the production of lightweight/porous geopolymers are rare (Li et al., 2015; Papa et al., 2015). In that sense, the possibility of producing lightweight waste based geopolymers assumes particular interest. Accord ingly, porous geopolymers were produced by adding hydrogen per oxide as blowing agent. To the best of our knowledge this is the first study concerning the production of porous WG containing geopolymers, which strengthens the innovative character of this investigation. The influence of blowing agent incorporation
Table 2

Chemical composition of metakaolin and waste glass.

\begin{tabular}{|c|c|c|}
\hline Oxides (\% (wt)) & MK & WG \\
\hline $\mathrm{SiO}_{2}$ & 54.40 & 70.57 \\
\hline $\mathrm{TiO}_{2}$ & 1.55 & 0.05 \\
\hline $\mathrm{Al}_{2} \mathrm{O}_{3}$ & 39.40 & 2.48 \\
\hline $\mathrm{Fe}_{2} \mathrm{O}_{3}$ & 1.75 & 0.28 \\
\hline $\mathrm{MgO}$ & 0.14 & 3.05 \\
\hline $\mathrm{CaO}$ & 0.10 & 5.59 \\
\hline $\mathrm{MnO}$ & 0.01 & 0.01 \\
\hline $\mathrm{Na}_{2} \mathrm{O}$ & - & 14.49 \\
\hline $\mathrm{K}_{2} \mathrm{O}$ & 1.03 & 1.35 \\
\hline $\mathrm{SO}_{3}$ & - & 0.19 \\
\hline $\mathrm{P}_{2} \mathrm{O}_{5}$ & 0.06 & 0.06 \\
\hline LOI & 2.66 & 0.95 \\
\hline Ratio of $\mathrm{SiO}_{2} / \mathrm{Al}_{2} \mathrm{O}_{3}$ & 1.38 & 28.46 \\
\hline
\end{tabular}

content on the geopolymers' porosity, apparent density and mechanical resistance was also considered.

\section{Experimental conditions}

\subsection{Materials}

Geopolymers were prepared using distinct mixtures of MK and WG as a source of silica. The MK was purchased under the name of Argical $^{\mathrm{TM}}$ M1200S from Univar ${ }^{\circledR}$, while WG was supplied by a Por tuguese lamp recycling company "Ambicare S.A.”. The WG comes from the recycling of fluorescent lamps that have been previously treated for recovery of mercury and rare earth elements; neverthe less, it is still severely contaminated with metal, plastic and other residues such as adhesives and resins. Albeit that their presence could be detrimental to geopolymerization, no separation attempt was performed, since we intended to use WG without expensive or complex treatments. The WGs were crushed in a mortar and sieved through a $75 \mu \mathrm{m}$ mesh prior to mixing.

Two different alkaline activators were prepared using hydrated sodium silicate (Chem Lab, Belgium; $8.5 \%$ (wt) $\mathrm{Na}_{2} \mathrm{O}, 28.5 \%$ (wt) $\mathrm{SiO}_{2}$ and $63 \%(\mathrm{wt}) \mathrm{H}_{2} \mathrm{O}$ ) and $\mathrm{NaOH}$ (reagent grade, 97\%, Sigma Aldrich), with an $\mathrm{Na}_{2} \mathrm{SiO}_{3}: \mathrm{NaOH}$ ratio of 1.43 . The $\mathrm{NaOH}$ solutions (10 and $12 \mathrm{M}$ ) were prepared by dissolution of 2040 mesh sodium hydroxide beads in distilled water.

The foamed geopolymers were prepared with a $3 \%(\mathrm{wt} / \mathrm{wt})$ hydrogen peroxide $\left(\mathrm{H}_{2} \mathrm{O}_{2}\right)$ solution.

Table 1

Geopolymer preparation: mixture composition, $\mathrm{NaOH}$ molarity and curing conditions.

\begin{tabular}{|c|c|c|c|c|c|c|c|c|}
\hline \multirow[t]{2}{*}{ Sample name } & \multicolumn{5}{|c|}{ Mixture proportion (\% (wt)) } & \multirow{2}{*}{$\begin{array}{l}\text { Activators nature } \\
\mathrm{NaOH}\left(\mathrm{mol} / \mathrm{dm}^{3}\right)\end{array}$} & \multirow[t]{2}{*}{ Curing conditions } & \multirow[t]{2}{*}{ Study objectives } \\
\hline & WG & MK & $\mathrm{Na}_{2} \mathrm{SiO}_{3}$ & $\mathrm{NaOH}$ & $\mathrm{H}_{2} \mathrm{O}_{2}$ & & & \\
\hline WG0-10M & 0.00 & 41.38 & 34.48 & 24.14 & - & 10 & $1^{\mathrm{a}}$ & Influence of WG incorporation \\
\hline WG12.5-10M & 5.17 & 36.21 & & & & & & \\
\hline WG25-10M & 10.34 & 31.03 & & & & & & \\
\hline WG37.5-10M & 15.52 & 25.86 & & & & & & \\
\hline WG50-10M & 20.69 & 20.69 & & & & & & \\
\hline WG0-12M & 0.00 & 41.38 & 34.48 & 24.14 & - & 12 & $1,2^{\mathrm{b}}$ and $3^{\mathrm{c}}$ & Influence of WG incorporation, $\mathrm{NaOH}$ \\
\hline WG12.5-12M & 5.17 & 36.21 & & & & & $1,2^{\mathrm{b}}$ and $3^{\mathrm{c}}$ & molarity and curing conditions \\
\hline WG25-12M & 10.34 & 31.03 & & & & & 1 & \\
\hline WG37.5-12M & 15.52 & 25.86 & & & & & $1,2^{\mathrm{b}}$ and $3^{\mathrm{c}}$ & \\
\hline WG50-12M & 20.69 & 20.69 & & & & & 1 & \\
\hline WG25-12M_0.03 & 10.34 & 31.03 & 34.47 & 24.14 & 0.01 & 12 & 1 & Influence of $\mathrm{H}_{2} \mathrm{O}_{2}$ content \\
\hline WG25-12M_0.15 & & & 34.43 & & 0.05 & & & \\
\hline WG25-12M_0.30 & & & 34.38 & & 0.10 & & & \\
\hline WG25-12M_0.60 & & & 34.27 & & 0.21 & & & \\
\hline
\end{tabular}

\footnotetext{
a 7 days $\left(40{ }^{\circ} \mathrm{C}\right.$ and $\left.65 \% \mathrm{RH}\right)+21$ days (room temperature in sealed bags).

b 1 day $\left(40{ }^{\circ} \mathrm{C}\right.$ and $\left.65 \% \mathrm{RH}\right)+27$ days (room temperature in sealed bags).

c 1 day $\left(40{ }^{\circ} \mathrm{C}\right.$ and $\left.65 \% \mathrm{RH}\right)+27$ days (room temperature in open conditions).
} 


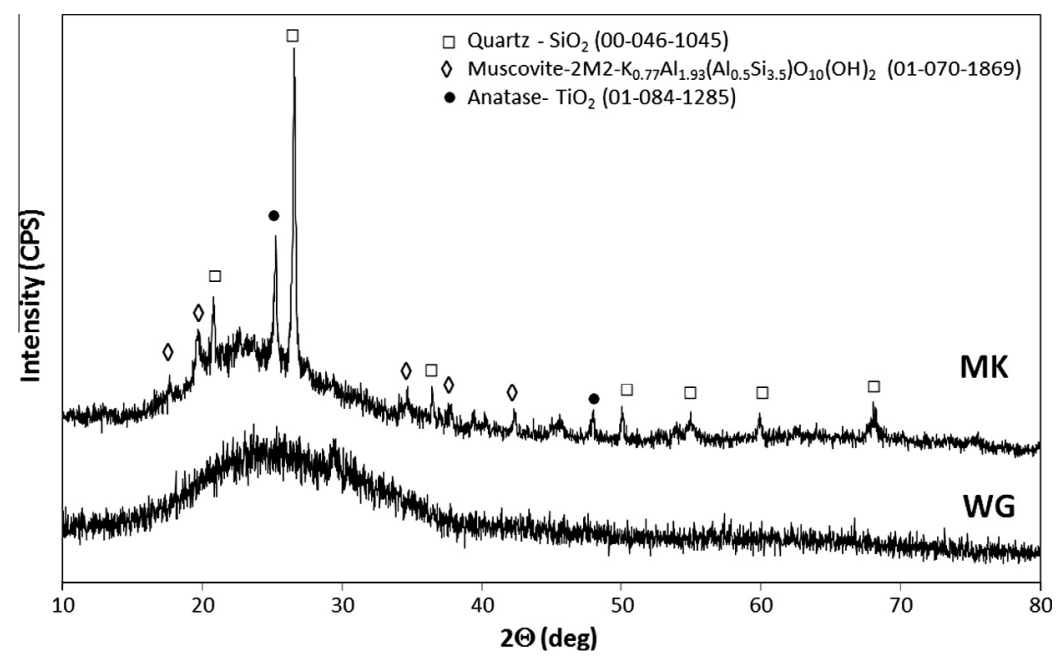

Fig. 1. XRD patterns metakaolin (MK) and fluorescent lamp waste glass (WG).

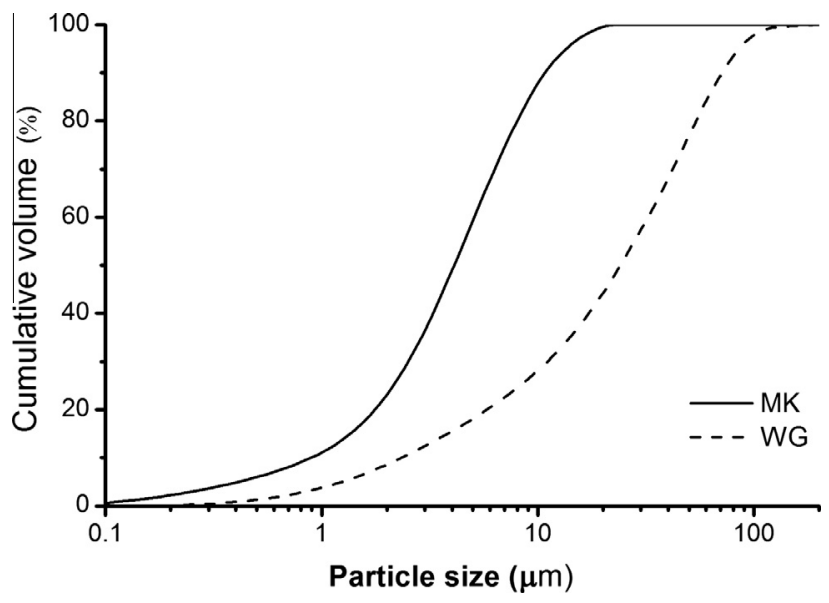

Fig. 2. Particle size distribution of metakaolin and fluorescent lamp waste glass.

\subsection{Geopolymer preparation}

To evaluate the suitability of WG as raw material in geopoly mers, distinct compositions were prepared in which MK was partly $(12.5,25,37.5$ and $50 \%$ (wt)) substituted by WG. The details of mix tures proportions, $\mathrm{NaOH}$ molarity and curing conditions are pre sented in Table 1.

The mixing was carried out by a mechanical process which involves: (1) homogenization of sodium silicate and $\mathrm{NaOH}$ solution (60 rpm, $5 \mathrm{~min}$ ) and (2) mixture of the alkaline solution with a pre viously homogenised mix of WG and MK (60 rpm, $10 \mathrm{~min}$ ). Then, the slurry was transferred to plastic moulds and sealed with a plas tic film. The samples were cured in controlled conditions $\left(40^{\circ} \mathrm{C}\right.$ and $65 \%$ relative humidity) using a climatic chamber for $24 \mathrm{~h}$. Afterwards, the specimens were demoulded and kept sealed in the same curing conditions until the 7th curing day. Then the sam ples were left in sealed bags at ambient temperature (closed con ditions) until the 28th curing day.

To evaluate the influence of curing conditions on the geopoly mer properties, a new set of formulations was prepared (see Table 1 for details). After demoulding on the 1st curing day, the samples were removed from the climatic chamber and then divided into two batches and cured in different conditions: (i) sealed bags at ambient temperature (closed conditions); and (ii) open conditions (ambient temperature and humidity), both until the 28th curing day.

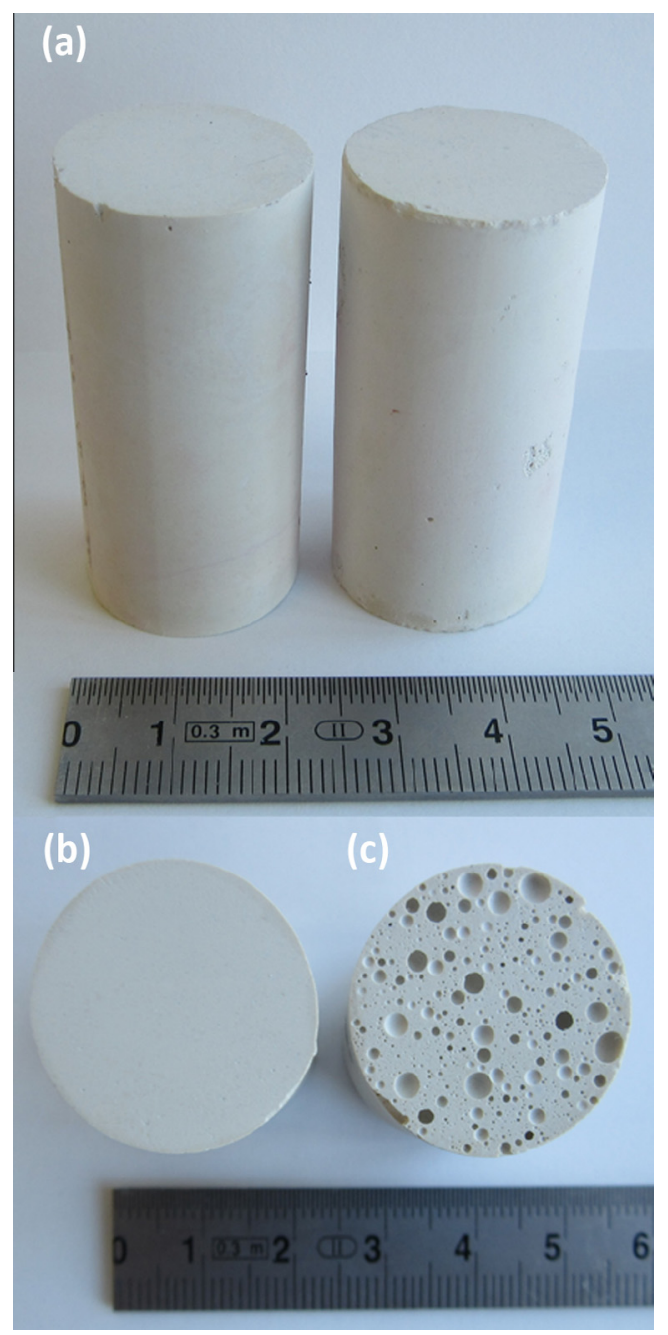

Fig. 3. (a) Side view of WG-containing geopolymers and top view of geopolymers produced (b) without and (c) with $0.30 \%$ (wt) of $\mathrm{H}_{2} \mathrm{O}_{2}$.

Different amounts of $\mathrm{H}_{2} \mathrm{O}_{2}$, at a fixed WG incorporation (25\% (wt)), were used to study the development of porous geopolymers. In these compositions, sodium silicate was substituted by 0.03 , $0.15,0.30$ and $0.60 \%(w t) \mathrm{H}_{2} \mathrm{O}_{2}$. The mixing procedure for these 
formulations was identical to the above mentioned, but requiring a third step ( $95 \mathrm{rpm}, 2 \mathrm{~min}$ ) corresponding to the addition of $\mathrm{H}_{2} \mathrm{O}_{2}$ to the blend.

\subsection{Material characterization}

Scanning electron microscopy (SEM Hitachi S4100 equipped with energy dispersion spectroscopy, EDS Rontec) was used, at $25 \mathrm{kV}$, to characterize the MK, the WG and to investigate the microstructure of the geopolymers. Optical analysis (Leica EZ4HD microscope) was used for the morphological analysis of the porous geopolymers. Samples were cut from 28 day cured geopolymers using a Struers Secotom 10 table top cutting machine.

The mineralogical compositions of MK, WG and geopolymer specimens with 28 days of cure were assessed by $\mathrm{X}$ ray powder diffraction (XRD). The XRD was conducted with a Rigaku Geigerflex $\mathrm{D} / \mathrm{max}$ Series instrument (CuK $\alpha$ radiation, $1080^{\circ}, 0.02^{\circ} 2 \theta$ step scan and $10 \mathrm{~s} / \mathrm{step}$ ), and phase identification by PANalytical X'Pert HighScore Plus software.

The chemical composition of WG and MK was obtained by using $\mathrm{X}$ ray fluorescence (Philips X'Pert PRO MPD spectrometer). The loss on ignition (LOI) at $1000^{\circ} \mathrm{C}$ was also determined. Particle size dis tribution was determined by laser diffraction (Coulter LS230 ana lyzer). The determination was performed by a laser diffraction technique (Fraunhofer method) for particles with a particle size from $0.4 \mu \mathrm{m}$ to $2000 \mu \mathrm{m}$, and simultaneously by PIDS (Polarization Intensity Differential Scattering) for lower particle sizes (between $0.4 \mu \mathrm{m}$ and $0.04 \mu \mathrm{m}$ ).

The compressive strength of samples cured for 1, 7 and 28 days was determined using a Universal Testing Machine (Shimadzu model AG $25 \mathrm{TA}$ ) running at a displacement rate of $0.5 \mathrm{~mm} \mathrm{~min}^{-1}$. Three cylindrical samples of each formulation $(22 \mathrm{~mm}$ diameter and $48 \mathrm{~mm}$ length) were tested and the average data reported. The specimen surfaces were polished flat and parallel before testing.

The Archimedes method (using water as the immersion fluid) was employed to evaluate the water absorption of the samples, while the bulk density was measured by the geometric method.

The true density of the geopolymer prepared without $\mathrm{H}_{2} \mathrm{O}_{2}$ (named WG25 12M), being $2.05 \mathrm{~g} / \mathrm{cm}^{3}$, was determined by the helium pycnometer technique (Multipycnometer, Quantachrome). The total porosity of the geopolymers prepared with distinct addi tions of hydrogen peroxide was then calculated following the sug gestions made by Landi et al. (2013).

The BET specific surface areas of the MK and WG were mea sured by $\mathrm{N}_{2}$ adsorption using a 5 point BET method on a Micromeritics Gemini 2380 surface area analyzer with ca. $250 \mathrm{mg}$ weight. Standard pre treatment conditions were $105^{\circ} \mathrm{C}$ and vacuum for $12 \mathrm{~h}$.

\section{Results and discussion}

\subsection{Metakaolin and waste glass characterization}

The chemical composition, presented in Table 2, shows that the most abundant oxides in the $\mathrm{WG}$ are $\mathrm{SiO}_{2}, \mathrm{Na}_{2} \mathrm{O}$ and $\mathrm{CaO}$, followed by $\mathrm{MgO}$ and $\mathrm{Al}_{2} \mathrm{O}_{3}$. In fact, this is the expected composition for a common glass. Fig. 1 presents the XRD patterns of WG and MK. The highly amorphous nature of WG can be seen from its XRD pat tern, which is supported by the absence of crystalline peaks. One of the most important factors in geopolymer formation is the reactive silica and alumina content (Torres Carrasco and Puertas, 2015). The expected high content of reactive silica of the WG indicates that it can be used as a source of silica on the preparation of geopolymers, but the low aluminum content $(\sim 2.5 \%$ (wt)) requires the incorporation of MK in the mixtures.
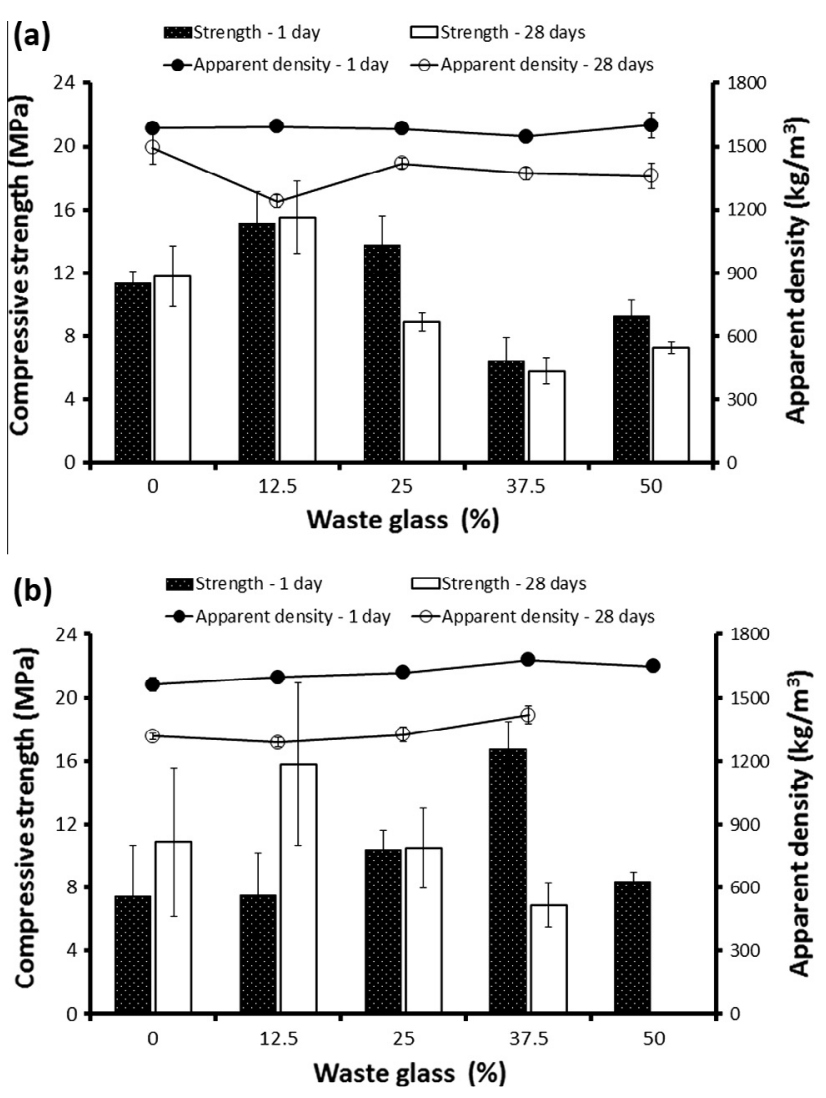

Fig. 4. Compressive strength and apparent density of WG-containing geopolymers activated with a mixture of sodium silicate solution and $\mathrm{NaOH}$ : (a) $10 \mathrm{M}$ and (b) $12 \mathrm{M} \mathrm{NaOH}$.

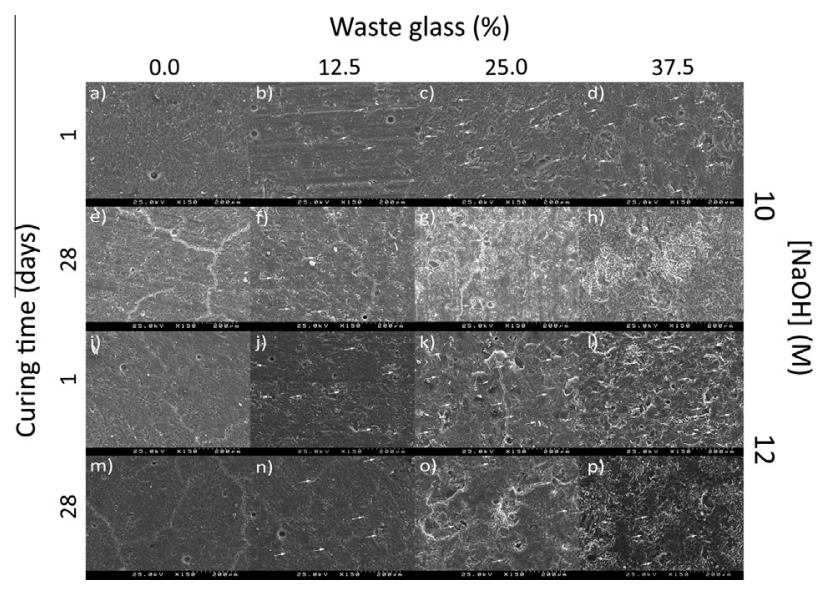

Fig. 5. SEM characterization of WG-containing geopolymers activated with different alkaline solutions, produced with distinct WG content $(0.0,12.5,25.0$ and 37.5\% $(w t))$ at the 1 st and 28 th curing days. The white arrows identify un-reacted waste glass particles.

The XRD pattern of MK shows a pronounced reflection between 20 and $30^{\circ}(2 \theta)$, which was attributed to the amorphous silica and alumina compounds. Nonetheless, a few crystalline peaks were also detected, such as those attributed to quartz, muscovite and anatase.

The WG displays a coarser particle size distribution (Fig. 2) than MK, with an estimated mean particle size of $31 \mu \mathrm{m}$ and $5 \mu \mathrm{m}$, for WG and MK, respectively. The specific surface area of WG $\left(3.92 \mathrm{~m}^{2} / \mathrm{g}\right)$, much lower than that of MK $\left(26.15 \mathrm{~m}^{2} / \mathrm{g}\right)$, supports the observed differences in particle size distribution. Differences 


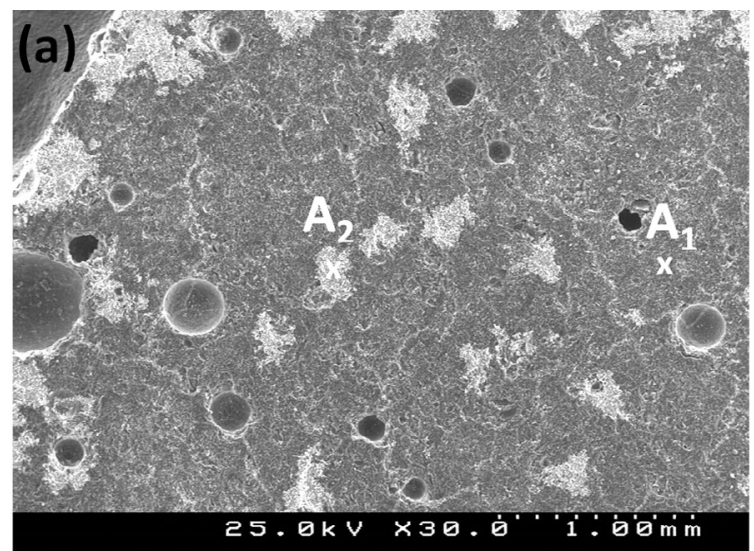

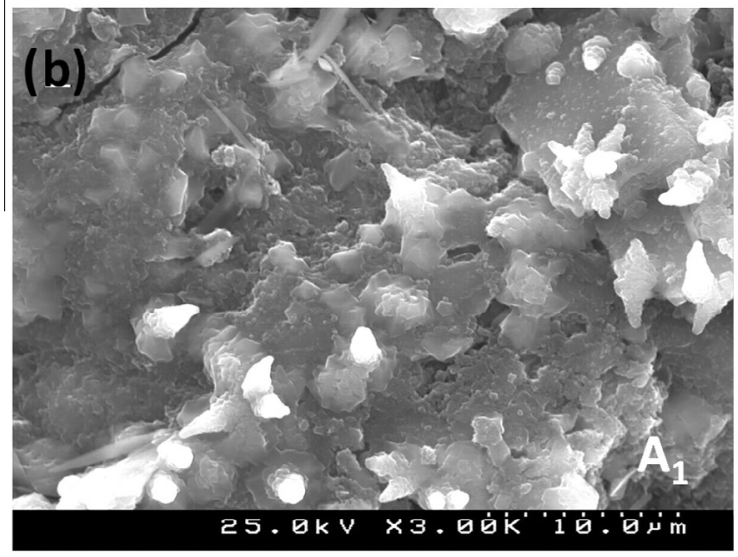

(d)

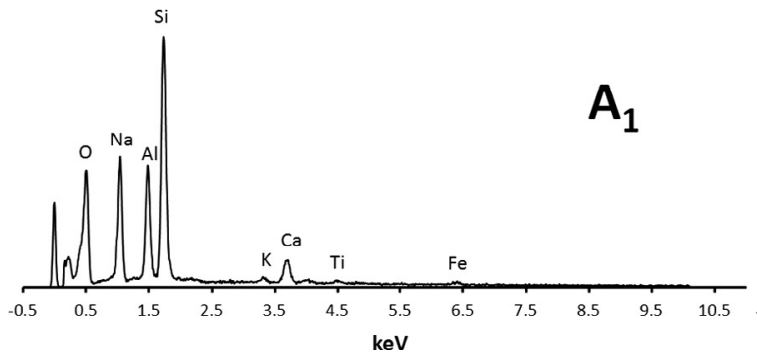

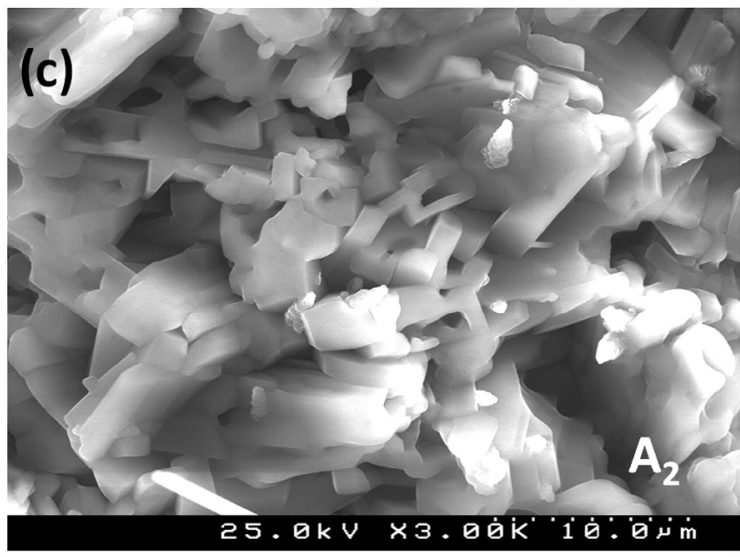

(e)

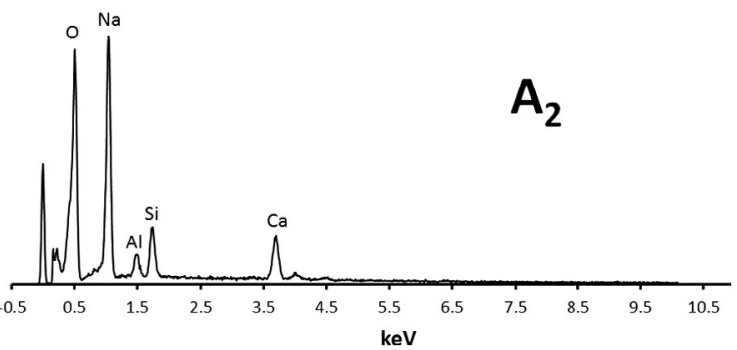

Fig. 6. (a-c) SEM micrographs of the composition coded as WG37.5-10M (cured for 28 days) and EDS spectrum at position (b) $A_{1}$ and (c) $A_{2}$.

in particle size are known to strongly affect the reactivity of raw materials (Nazari et al., 2011), and hence the geopolymer strength (He et al., 2012).

\subsection{Geopolymers characterization}

\subsubsection{Influence of WG incorporation and $\mathrm{NaOH}$ molarity}

Fig. 3a presents typical photographs of the produced geopoly mers, while Fig. 3b and c illustrate the differences between the dense and the porous samples (discussed in Section 3.2.3).

Fig. 4a and b presents the compressive strength and apparent density of WG containing geopolymers activated with sodium sil icate and $\mathrm{NaOH}$, in which the molarity of the latter was respec tively $10 \mathrm{M}$ and $12 \mathrm{M}$. The influence of the WG incorporation level and the $\mathrm{NaOH}$ molarity is obvious. Fig. 4a shows that an incorporation of $12.5 \%(\mathrm{wt}) \mathrm{WG}$ improved the mechanical resis tance (15.5 MPa) in comparison with pure MK based geopolymers (11.8 $\mathrm{MPa}$ ) at the 28th day, while further WG incorporation has the opposite effect. As the WG content rises the initial $\mathrm{SiO}_{2} / \mathrm{Al}_{2} \mathrm{O}_{3}$ ratio of the mixtures increases, with expected positive effects on the strength of the activated mixtures (Ozer and Soyer Uzun, 2015), since $\mathrm{Si}-\mathrm{O}-\mathrm{Si}$ bonds are stronger than $\mathrm{Si}-\mathrm{O}-\mathrm{Al}$ and $\mathrm{Al}-\mathrm{O}-\mathrm{Al}$ bonds (Bobirică et al., 2015). However, this relationship is only observed when the WG content matches $12.5 \%(\mathrm{wt})$. There are two possible explanations for these results: (i) the substitution of MK by WG reduced the silicon and aluminum ions' release rates, due to the lower and slower dissolution rate of WG in comparison with that of MK, which affects the strength development; and (ii) raising the WG content increased the number of unreacted glass particles. Indeed, SEM micrographs shown in Fig. 5 clearly demon strate an increase in their number (identified by white arrows) when the WG content rises, suggesting a lower degree of the geopolymeric reaction and, therefore, a worse mechanical perfor mance. Similar findings have been reported for WG containing geopolymers (Hao et al., 2013; Lin et al., 2012), and for MK based geopolymers which were produced with distinct $\mathrm{Si} / \mathrm{Al}$ ratios (Duxson et al., 2005).

Khale and Chaudhary (2007) suggested that the Si/Al ratio must lie between 3.3 and 4.5 in order to form strong geopolymeric prod ucts. Below or above these limits, as in the compositions with WG 

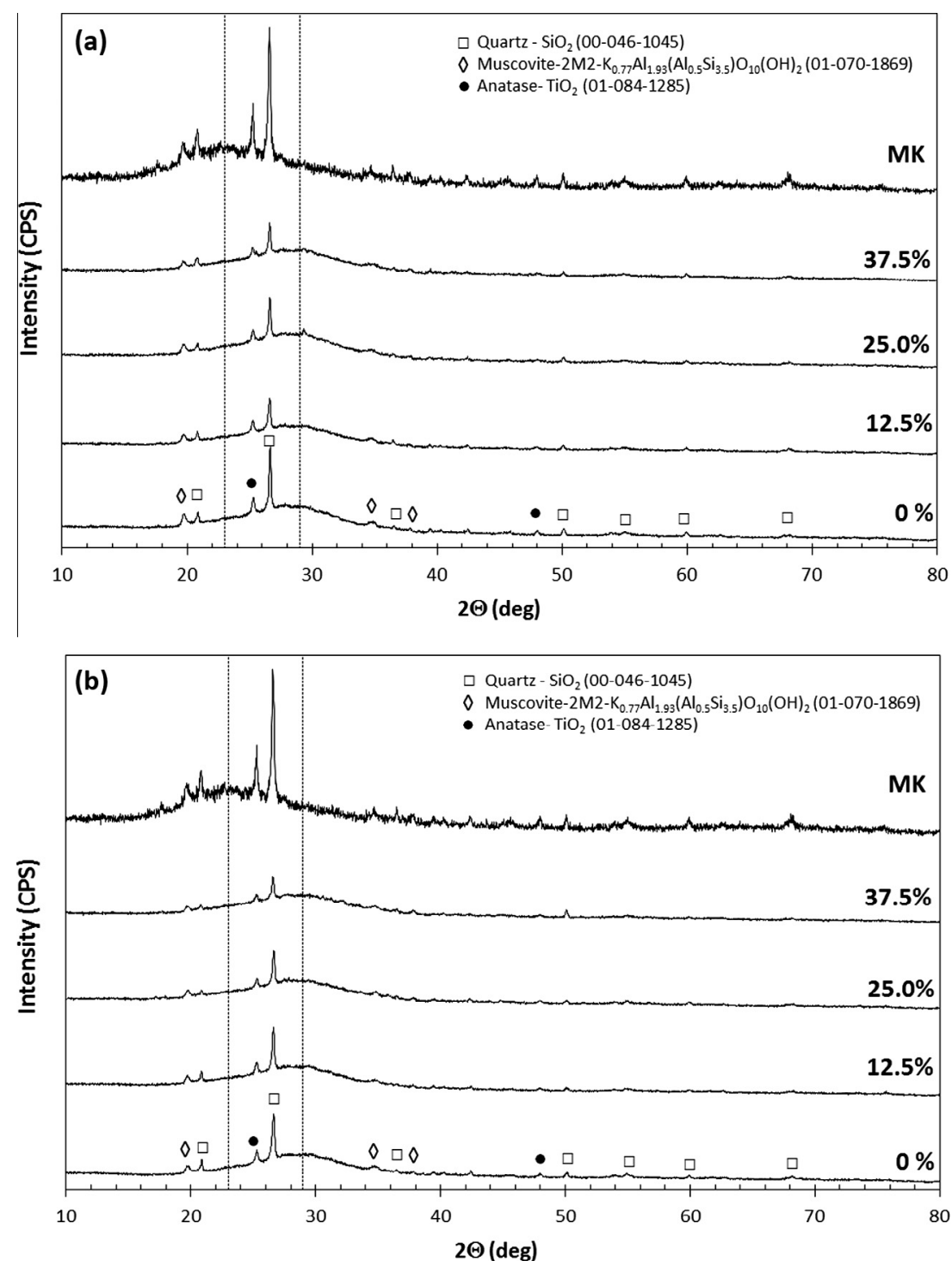

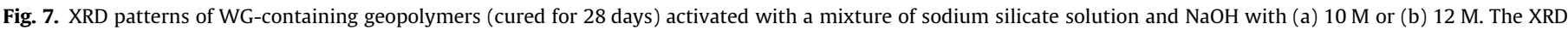
pattern of the MK was included for comparison.

higher than $25 \%$ (wt), the polymerized network is less stable, and this is in agreement with our results.

Results also show a small increase in the compressive strength with curing time for the pure MK based geopolymer and for the $12.5 \%$ (wt) WG geopolymers, while compositions containing higher WG contents exhibited the opposite behavior. The strength losses can be attributed to phase changes occurring during aging (Lloyd, 2009). Indeed, SEM micrographs (see Fig. 5a h) show sig nificant changes to the geopolymers' morphology with curing time for the compositions prepared with WG content higher than $25 \%$ $(\mathrm{wt})$. The microstructural modifications are visually confirmed by the SEM micrographs shown in Fig. 6a c. Several bright areas are observed (e.g. $A_{2}$ ), which are characterized by a more porous microstructure, essentially rich in $\mathrm{Na}$, suggesting expansion of the reactive parts. Those areas contrast with the darker and denser aluminosilicate gel (e.g. $A_{1}$ ). Accordingly, the strength losses were attributed to the porosity increase during curing, possibly pro moted by the high free alkalis content in these compositions (Pascual et al., 2014). In fact, Lloyd et al. (2008) reported that the increase of silica amount promotes alkalis diffusion.
However, these phase changes occurring during aging are not observed in the XRD patterns. The XRD patterns of geopolymers cured for 28 days, shown in Fig. 7, are identical to those cured for 1 day (not shown here by the sake of brevity). The position of the diffraction peaks in the WG containing geopolymer coincides with those of the MK (included in Fig. 7 for comparison), while peak intensity is attenuated as the WG content rises. All XRD pat terns show the presence of a pronounced hump between 20 and $40^{\circ}(2 \theta)$ typically observed in geopolymers (Zhang et al., 2014), while the center of this hump is shifted toward higher $2 \theta$ values in comparison with that observed in MK (from ca. $23^{\circ}(2 \theta)$ to $29^{\circ}$ $(2 \theta)$ ). This shift has been associated with the formation of new amorphous phases (Zhang et al., 2012), being indicative of the geopolymeric reaction. Further evidence of geopolymerization occurrence was the formation of a geopolymeric gel (see Fig. 8b) essentially composed of $\mathrm{Si}, \mathrm{Al}$ and $\mathrm{Na}$, which was observed in all compositions.

The geopolymers' apparent density decreased during aging (see Fig. 4), which was attributed to water release occurring with geopolymerization and upon curing (Pimraksa et al., 2011). 

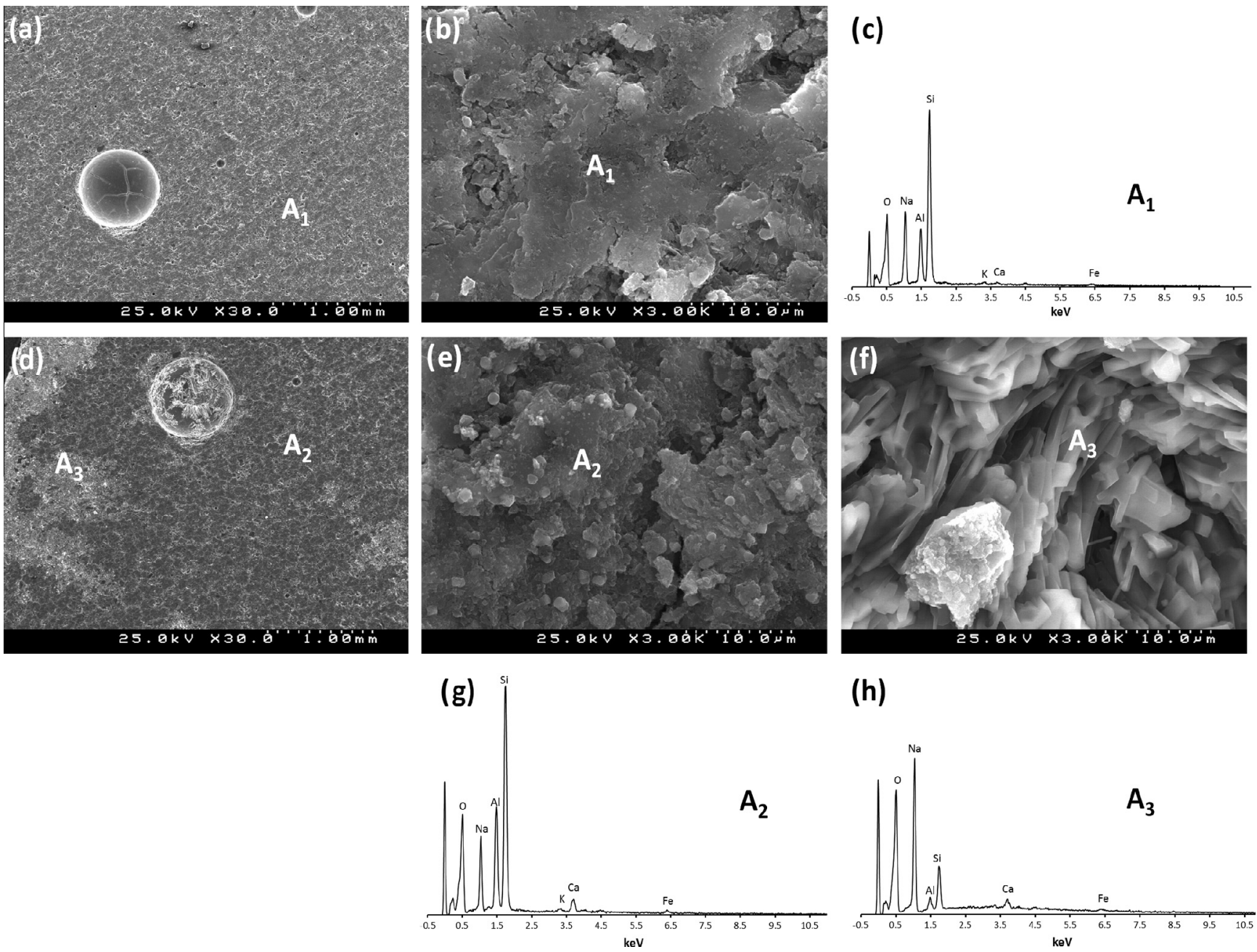

(h)

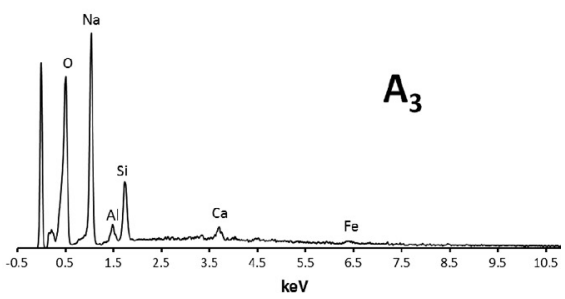

Fig. 8. SEM micrographs and EDS spectrum of the composition coded as WG37.5-12M cured for (a-c) 1 day and (d-h) 28 days.

Generally, a gradual increase in the geopolymer strength is observed along with an increase in the activator concentration (Pimraksa et al., 2011; Torres Carrasco and Puertas, 2015), due to the higher dissolution of the aluminosilicate sources. Nevertheless, very high alkali concentration could delay the geopolymerization process as a result of limited ion mobility (Alonso and Palomo, 2001). Fig. 4b shows that when the WG is below 25\% (wt), lower compressive strengths after the 1 st curing day are obtained, while the strengths on the 28th day were similar to those recorded in the compositions prepared with $10 \mathrm{M}$. Therefore, increasing the $\mathrm{NaOH}$ concentration delayed the strength evolution, but not the ultimate strength. Furthermore, a distinct behavior was observed for the composition containing 37.5\% (wt) WG: a significantly higher strength was observed after the 1 st day (16.8 MPa) in comparison with the composition prepared using $10 \mathrm{M} \mathrm{NaOH}$ (6.4 MPa). For this composition, significant strength losses with aging were observed, which is in agreement with the morphological modifica tions shown in Fig. $5 \mathrm{i}$ p. These results indicate that the amorphous gel detected on the 1st day (Fig. 8b) was unstable. Indeed, the SEM micrographs and the EDS spectrum shown in Fig. 8 reveal a poros ity increase, with a simultaneous change in the geopolymerization products (from a predominantly aluminosilicate gel to a sodium silicate gel). This phenomenon was even more severe in the com position prepared with $50 \%(\mathrm{wt}) \mathrm{WG}$. In fact, dramatic microstruc tural changes occurred within the first 7 curing days (at $40{ }^{\circ} \mathrm{C}$ and $65 \% \mathrm{RH}$ ), which induced several micro cracks on the test speci mens. For that reason, the compressive strength on the 28th day for this composition was not measured. Redden and Neithalath (2014) reported that the presence of higher alkalinity in the pore solution induces disintegration of the gel, which is in agreement with our results. Furthermore the selected curing conditions (imposing high humidity levels throughout curing) could adversely affect the strength evolution (to be further discussed in Section 3.2.2).

\subsubsection{Influence of curing conditions}

Three different curing conditions (see descriptions in Table 1) were applied to investigate the influence of both curing time (at slightly elevated temperature) and humidity level (open/closed conditions) on the geopolymer strength development. Fig. 9 pre sents the compressive strength after the 1st, 7th and 28th curing days for the different WG containing geopolymers. For the pure MK based geopolymer, an increase in compression strength up to the 7th day is observed for all conditions, but afterwards a decrease is seen for condition 2 . The higher humidity levels (imposed in con dition 1 and 2) hinder the water evaporation and, as a conse quence, increase the available alkali solution (Izquierdo et al., 2010) which is detrimental to the strength development. On the contrary, open curing conditions (condition 3) enable water evap oration, promoting a gain in strength with curing time. Indeed, results demonstrate that this condition promoted the highest strength values at the 28th day, and even with a lower curing time ( 1 day) at $40{ }^{\circ} \mathrm{C}$ in comparison with the specimens cured under condition 1 ( 7 days). For $12.5 \%$ (wt) WG, the compressive strength 

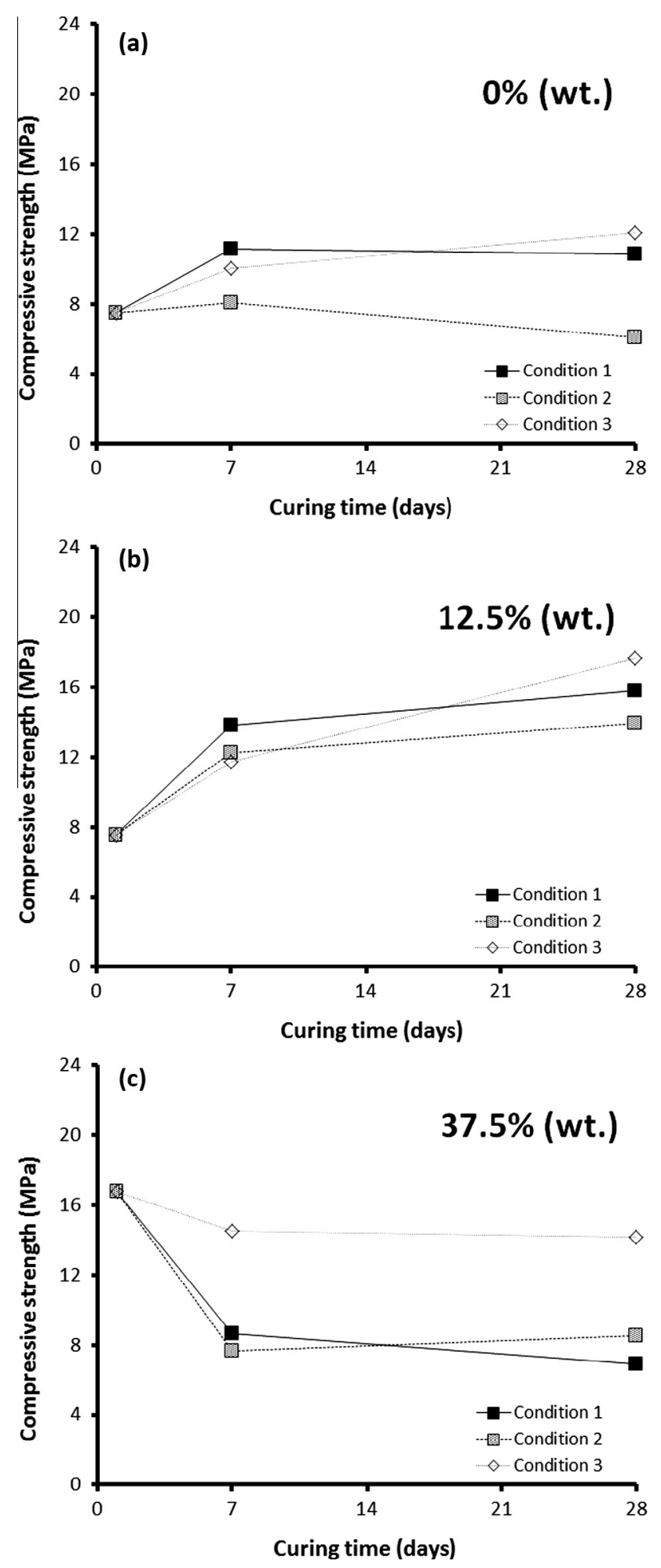

Fig. 9. Influence of curing conditions on the compressive strength of WGcontaining geopolymers.

increased with curing time for all studied conditions, although once again open curing conditions promoted the highest strength improvement, while the combination of closed conditions and lower curing time at $40{ }^{\circ} \mathrm{C}$ (condition 2) induced the lowest ulti mate strength.

The compressive strength of all compositions prepared with $37.5 \%$ (wt) WG initially decreased from the 1 st to the 7 th day, before stabilizing up to the 28th day. Nevertheless, losses were substantially smaller in condition 3 , suggesting that for high WG content, curing method (open or closed) rather than curing time (at $40^{\circ} \mathrm{C}$ ) is the governing parameter affecting strength development.

\subsubsection{Influence of hydrogen peroxide content}

As mentioned in the experimental section, a new set of formu lations were prepared by adding distinct amounts of hydrogen per oxide to a previously prepared geopolymer slurry. Fig. 10 present typical optical and SEM micrographs of the geopolymers prepared with variable amounts of hydrogen peroxide. The content of hydro gen peroxide dictated the volume, area and number of pores. This observation is corroborated by the water absorption and porosity values presented in Table 3. As observed, the increase in the hydro gen peroxide content increases the water absorption and total porosity, while decreasing the apparent density.

The effect of the hydrogen peroxide content on the apparent density and total porosity is illustrated in Fig. 11. Results show a threshold around $0.30 \%(w t)$ hydrogen peroxide incorporation: below this value there is a striking variation in both variables (region I); while further increases in the hydrogen peroxide above $0.30 \%$ (wt) produce only modest variations (region II).

An inverse correlation between porosity and compressive strength has been widely reported (Gibson and Ashby, 1997; Novais et al., 2015; Rice, 1996). Indeed, a significant decrease in the compressive strength of geopolymers (see Table 3) when the porosity increases (samples with increasing $\mathrm{H}_{2} \mathrm{O}_{2}$ levels) was observed. For example, a fourfold decrease in the compressive strength (from 11.2 to $2.9 \mathrm{MPa}$ ) of geopolymers (cured for 7 days) was observed when $0.6 \%$ (wt) $\mathrm{H}_{2} \mathrm{O}_{2}$ was added. These results demonstrate that the compressive strength can be controlled by the hydrogen peroxide content, and therefore can be tailored con sidering the envisaged application.

Values of the specific strength (strength divided by density) for the produced geopolymers were estimated to evaluate their mechanical efficiency. The specific strength of the non porous geopolymer (prepared without hydrogen peroxide) was $8.8 \mathrm{MPa} \mathrm{cm}^{3} / \mathrm{g}$, while for the porous geopolymers it ranged between 8.9 and $3.5 \mathrm{MPa} \mathrm{cm} / \mathrm{g}$. This is superior to others previ ously reported in the literature: (i) $2.7 \mathrm{MPa} \mathrm{cm} / \mathrm{g}$ for foamed perlite based geopolymers (Vaou and Panias, 2010) and (ii) 2.9 MPa $\mathrm{cm}^{3} / \mathrm{g}$ for fly ash based geopolymers (Feng et al., 2015).

The production of lightweight geopolymers has attracted increasing attention, which is explained not only due to their low cost and green technology production, but mainly due to signifi cant technical advantages over conventional materials. A wide range of applications are envisioned, for example as thermal insu lation (Novais et al., 2016), heavy metal adsorbents (Tang et al., 2015) and pH buffering (Bumanis et al., 2015) materials. At the cur rent level of development, these WG containing geopolymers pre sent apparent densities as low as $820 \mathrm{~kg} / \mathrm{m}^{3}$, which suggest their application as thermal insulation reinforcement materials. Further more, the compressive strength values attained (2.9 MPa after 7 days curing) suggest that a further reduction in their density is feasible, which widens the application range of these novel materials.

\section{Conclusions}

This study evaluated the possibility of using waste glass from end of life fluorescent lamps as raw material in the geopolymer production. This unexplored waste glass was used to partially replace metakaolin, with obvious advantages both from environ mental and economic viewpoints. 

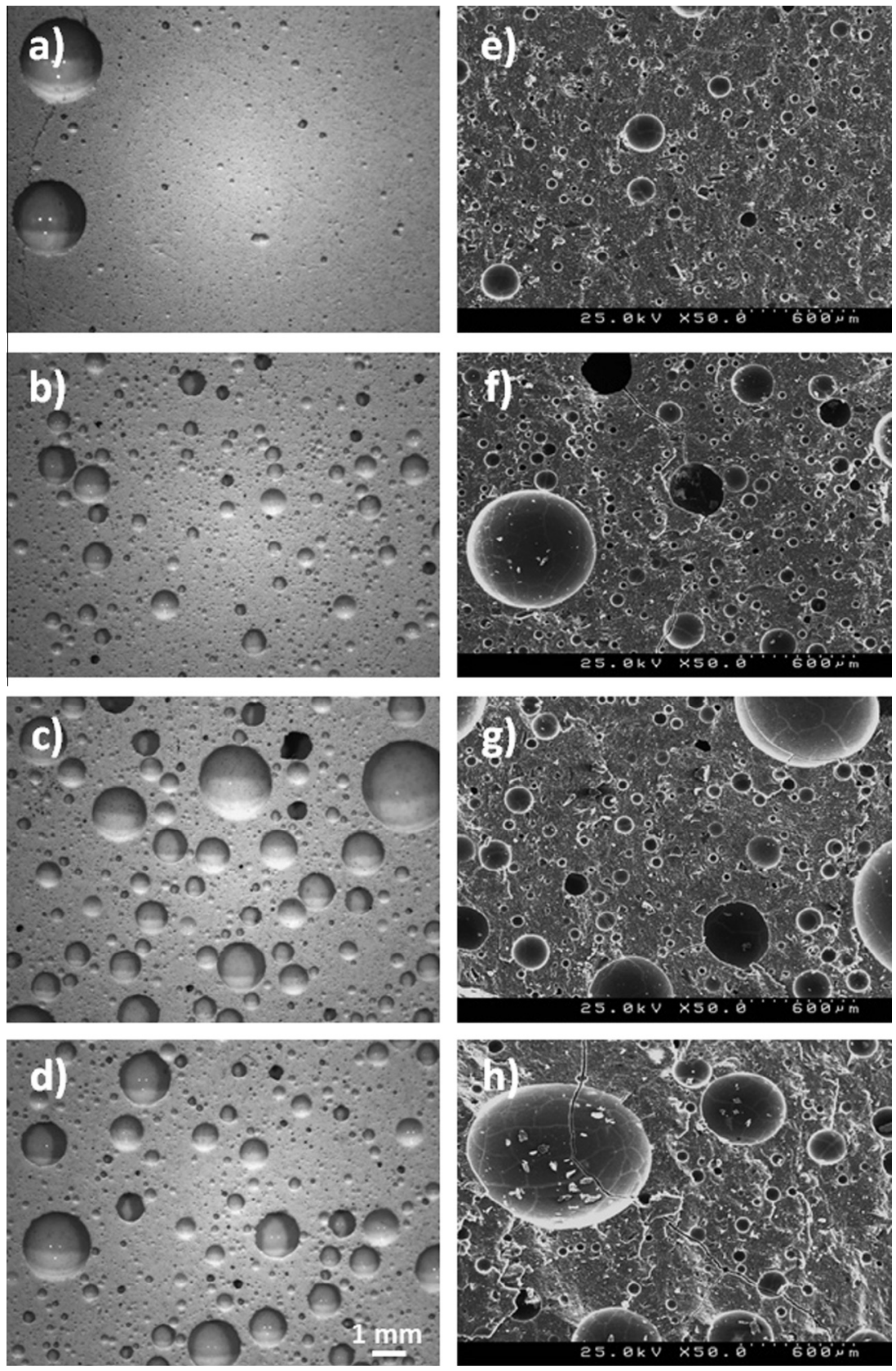

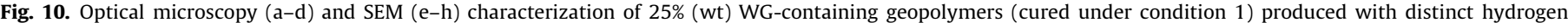
peroxide content: $0.03 \%(w t)$ (a and e), $0.15 \%$ (wt) (b and f), $0.30 \%$ (wt) (c and g) and $0.60 \%$ (wt) (d and h).

Table 3

Water absorption, apparent density and total porosity of $25 \%$ (wt) WG-containing geopolymers prepared with distinct amounts of $\mathrm{H}_{2} \mathrm{O}_{2}$ cured for 7 days (under condition 1).

\begin{tabular}{lllll}
\hline $\mathrm{H}_{2} \mathrm{O}_{2}$ content\% (wt) & 0.03 & 0.15 & 0.30 & 0.60 \\
Water absorption (\%) & 19.99 & 26.59 & 32.45 & 35.06 \\
$\begin{array}{c}\text { Apparent density } \\
\quad\left(\mathrm{g} / \mathrm{cm}^{3}\right)\end{array}$ & $1.26 \pm 0.02$ & $1.05 \pm 0.04$ & $0.87 \pm 0.04$ & $0.82 \pm 0.12$ \\
$\begin{array}{l}\text { Total porosity (\%) } \\
\begin{array}{c}\text { Compressive strength } \\
(\mathrm{MPa})\end{array}\end{array}$ & 43.4 & 52.8 & 60.9 & 63.1 \\
\hline
\end{tabular}

Parameters such as the waste glass incorporation and the curing conditions were found to significantly affect the properties of the produced WG containing geopolymers, while the $\mathrm{NaOH}$ molarity plays a less important role. Raising the $\mathrm{NaOH}$ molarity delays the geopolymerization, but the ultimate strength (after 28 days of cur ing) was similar for the studied molarities.

Results show that the incorporation of $12.5 \%(\mathrm{wt})$ WG increases the compressive strength by nearly $46 \%$, while higher amounts have the opposite result in comparison with the pure MK based geopolymer.

Results also demonstrate the tremendous impact of curing con ditions on the WG containing geopolymers' compressive strength evolution. The strength losses observed for the high WG containing geopolymers cured in sealed bags can be strongly mit igated if open curing is used. The latter enables the incorporation of up to $37.5 \%$ (wt) WG (14 MPa) without any strength compromise.

The possibility of producing lightweight WG containing geopolymers was also evaluated by using hydrogen peroxide as blowing agent. Lightweight geopolymers showing apparent 


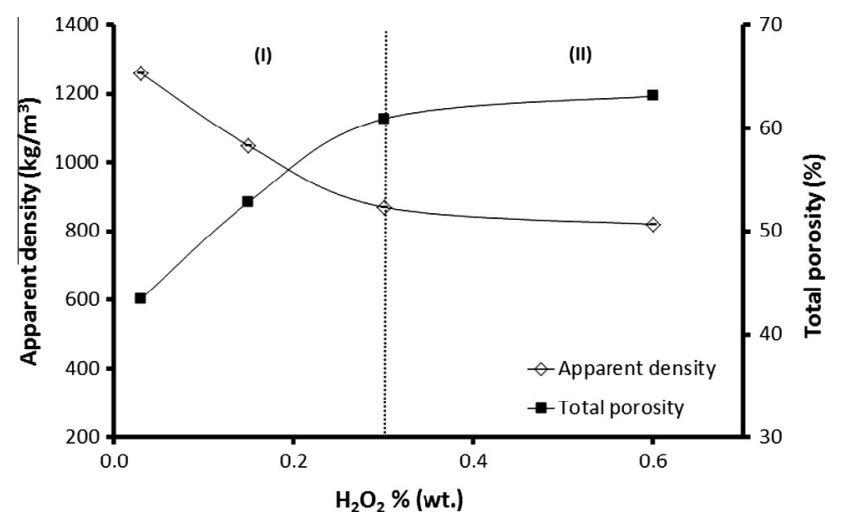

Fig. 11. Apparent density and total porosity of $25 \%$ (wt) WG-containing geopolymers (cured for 7 days under condition 1) produced with distinct $\mathrm{H}_{2} \mathrm{O}_{2}$ amounts.

density as low as $820 \mathrm{~kg} / \mathrm{m}^{3}$ and compressive strength of $2.9 \mathrm{MPa}$ were fabricated. The content of hydrogen peroxide controls the geopolymers' physical properties (porosity, apparent density and compressive strength), and thus these can be tailored considering the application envisioned.

This work demonstrates the feasibility of producing light weight, waste based geopolymers with potential as construction materials, using a simple and eco friendly approach. Furthermore, the incorporation of local and unexplored residue (fluorescent lamp waste glass) is a positive contribute toward sustainable construction.

\section{Acknowledgements}

This work was developed within the scope of the project CICECO Aveiro Institute of Materials, POCI 010145 FEDER 007679 (FCT Ref. UID /CTM /50011/2013), financed by national funds through the FCT/MEC and when appropriate co financed by FEDER under the PT2020 Partnership Agreement. The authors acknowledge the assistance of Dr. R.C. Pullar with editing English language in this paper.

\section{References}

Alonso, S., Palomo, A., 2001. Alkaline activation of metakaolin and calcium hydroxide mixtures: influence of temperature, activator concentration and solids ratio. Mater. Lett. 47, 55-62.

Arulrajah, A., Ali, M.M.Y., Disfani, M.M., Horpibulsuk, S., 2014. Recycled-glass blends in pavement base/subbase applications: laboratory and field evaluation. ASCE J. Mater. Civil Eng. 26 (7).

Benhelal, E., Zahedi, G., Haslenda, H., 2012. A novel design for green and economical cement manufacturing. J. Clean. Prod. 22, 60-66.

Bobirică, C., Shim, J.H., Pyeon, J.H., Park, J.Y., 2015. Influence of waste glass on the microstructure and strength of inorganic polymers. Ceram. Int. 41, 1363813649.

Bumanis, G., Bajare, D., Rugele, K., 2015. The effect of alkaline material particle size on adjustment ability of buffer capacity. Medziagotyra 21, 405-409.

Chen, C., Habert, G., Bouzidi, Y., Jullien, A., 2010. Environmental impact of cement production: detail of the different processes and cement plant variability evaluation. J. Clean. Prod. 18 (5), 478-485.

Cucchiella, F., D'Adamo, I., Koh, S.C.L., Rosa, P., 2015. Recycling of WEEs: an economic assessment of present and future e-waste streams. Renew. Sustain. Energy Rev. 51, 263-272.

Cyr, M., Idir, R., Poinot, T., 2012. Properties of inorganic (geopolymer) mortars made of glass cullet. J. Mater. Sci. 47, 2782-2797.

Duxson, P., Provis, J.L., Lukey, G.C., Mallicoat, S.W., Kriven, W.M., van Deventer, J.S.J., 2005. Understanding the relationship between geopolymer composition, microstructure and mechanical properties. Colloids Surf. A: Physicochem. Eng. Aspects 269, 47-58.

Feng, J., Zhang, R., Gong, L., Li, Y., Cao, W., Cheng, X., 2015. Development of porous fly-ash-based geopolymer with low thermal conductivity. Mater. Des. 65, 529533.

Gibson, L.J., Ashby, M.F., 1997. Cellular Solids: Structure and Properties, second ed. Cambridge University Press, Cambridge, UK.
Hao, H.C., Lin, K.-L., Wang, D.Y., Chao, S.-J., Shiu, H.S., Cheng, T.-W., Hwang, C.-L. 2013. Utilization of solar panel waste glass for metakaolinite-based geopolymers synthesis. Environ. Prog. Sustain. Energy 32, 797-803.

He, J., Zhang, J., Yu, J.Y., Zhang, G., 2012. The strength and microstructure of two geopolymers derived from metakaolin and red mud-fly ash admixture: a comparative study. Constr. Build. Mater. 30, 80-91.

Imteaz, M.A., Ali, M.M.Y., Arulrajah, A., 2012. Possible environmental impacts of recycled glass used as a pavement base material. Waste Manage. Res. 30, 917921.

Innocenzi, V., De Michelis, I., Ferella, F., Vegliò, F., 2013. Recovery of yttrium from cathode ray tubes and lamps' fluorescent powders: experimental results and economic simulation. Waste Manage. 33, 2390-2396.

Izquierdo, M., Querol, X., Phillipart, C., Antenucci, D., Towler, M., 2010. The role of open and closed curing conditions on the leaching properties of fly ash-slagbased geopolymers. J. Hazard. Mater. 176, 623-628.

Jang, M., Hong, S.M., Park, J.K., 2005. Characterization and recovery of mercury from spent fluorescent lamps. Waste Manage. 25, 5-14.

Kajaste, R., Hurme, M., 2016. Cement industry greenhouse gas emissions management options and abatement cost. J. Clean. Prod. 112, 4041-4052.

Ke, X., Bernal, S.A., Ye, N., Provis, J.L., Yang, J., 2015. One-part geopolymers based on thermally treated red mud/NaOH blends. J. Am. Ceram. Soc. 98, 5-11.

Khale, D., Chaudhary, R., 2007. Mechanism of geopolymerization and factors influencing its development: a review. J. Mater. Sci. 42, 729-746.

Komnitsas, K., Zaharaki, D., 2007. Geopolymerization: a review and prospects for the minerals industry. Miner. Eng. 20, 1261-1277.

Landi, E., Medri, V., Papa, V., Dedecek, J., Klein, P., Benito, P., Vaccari, A., 2013. Alkalibonded ceramics with hierarchical tailored porosity. Appl. Clay Sci. 73, 56-64.

Lee, C.-H., Popuri, S.R., Peng, Y.-H., Fang, S.-S., Lin, K.L., Fan, K.-S., Chang, T.-C., 2015 Overview on industrial recycling technologies and management strategies of end-of-life fluorescent lamps in Taiwan and other developed countries. J. Mater. Cycles Waste Manage. 17, 312-323.

Li, R., Wu, G., Jiang, L., Sun, D., 2015. Characterization of multi-scale porous structure of fly-ash/phosphate geopolymer hollow sphere structures: from submillimeter to nano-scale. Micron 68, 54-58.

Lin, K.L., Shiu, H.S., Shie, J.L., Cheng, T.W., Hwang, C.L., 2012. Effect of composition on characteristics of thin film transistor liquid crystal display (TFT-LCD) waste glass-metakaolin-based geopolymers. Constr. Build. Mater. 36, 501-507.

Lloyd, R.R., 2009. Accelerated ageing of geopolymers. In: Provis, J.L., van Deventer, J. S.J. (Eds.), Geopolymers: Structures, Processing, Properties and Industrial Applications. Woodhead Publishing Ltd., Cambridge, p. 139.

Lloyd, R.R., Provis, J.L., van Deventer, J.S.J., 2008. Microscopy and microanalysis of inorganic polymer cements. 1: remnant fly ash particles. J. Mater. Sci. 44, 608619.

McLellan, B.C., Williams, R.P., Lay, J., van Riessen, A., Corder, G.D., 2011. Costs and carbon emissions for geopolymer pastes in comparison to ordinary Portland cement. J. Clean. Prod. 19, 1080-1090.

Nazari, A., Bagheri, A., Riahi, S., 2011. Properties of geopolymer with seeded fly ash and rice husk bark ash. Mater. Sci. Eng., A 528, 7395-7401.

Novais, R.M., Buruberri, L.H., Ascensão, G., Seabra, M.P., Labrincha, J.A., 2016. Porous biomass fly ash-based geopolymers with tailored thermal conductivity. J. Clean. Prod. 119, 99-107.

Novais, R.M., Seabra, M.P., Labrincha, J.A., 2015. Lightweight dense/porous bilayered ceramic tiles prepared by double pressing. J. Mater. Process. Technol 216, 169-177.

Ozer, I., Soyer-Uzun, S., 2015. Relations between the structural characteristics and compressive strength in metakaolin based geopolymers with different molar $\mathrm{Si} /$ Al ratios. Ceram. Int. 41, 10192-10198.

Papa, E., Medri, V., Benito, P., Vaccari, A., Bugani, S., Jaroszewicz, J., Swieszkowski, W., Landi, E., 2015. Synthesis of porous hierarchical geopolymer monoliths by ice-templating. Micropor. Mesopor. Mater. 215, 206-214.

Pascual, A.B., Tognonvi, M.T., Tagnit-Hamou, A., 2014. Waste glass powder-based alkali-activated mortar. Int. J. Res. Eng. Technol. 03, 15-19.

Pelisser, F., Guerrino, E.L., Menger, M., Michel, M.D., Labrincha, J.A., 2013 Micromechanical characterization of metakaolin-based geopolymers. Constr. Build. Mater. 49, 547-553.

Pimraksa, K., Chindaprasirt, P., Rungchet, A., Sagoe-Crentsil, K., Sato, T., 2011. Lightweight geopolymer made from highly porous siliceous materials with various $\mathrm{Na}_{2} \mathrm{O} / \mathrm{Al}_{2} \mathrm{O}_{3}$ and $\mathrm{SiO}_{2} / \mathrm{Al}_{2} \mathrm{O}_{3}$ ratios. Mater. Sci. Eng., A 528, 6616-6623.

Puertas, F., Torres-Carrasco, M., 2014. Use of waste glass as an activator in the preparation of alkali-activated slag. Mechanical strength and paste characterisation. Cem. Concr. Res. 57, 95-104.

Rice, R.W., 1996. Evaluation and extension of physical property-porosity models based on minimum solid area. J. Mater. Sci. 31, 102-118.

Redden, R., Neithalath, N., 2014. Microstructure, strength, and moisture stability of alkali activated glass powder-based binders. Cem. Concr. Compos. 45, 46-56.

Santa, A.R.B., Bernardin, A.M., Gracher, R.H., Cabral, N.K., 2013. Geopolymer synthetized from bottom coal ash and calcined paper sludge. J. Clean. Prod. 57, 301-307.

Tang, Q., Ge, Y.-Y., Wang, K.-T., He, Y., Cui, X.-M., 2015. Preparation and characterization of porous metakaolin-based inorganic polymer spheres as an adsorbent. Mater. Des. 88, 1244-1249.

Torres-Carrasco, M., Puertas, F., 2015. Waste glass in the geopolymer preparation. Mechanical and microstructural characterization. J. Clean. Prod. 90, 397-408. 
Tzanakos, K., Mimilidou, A., Anastasiadou, K., Stratakis, A., 2014. Solidification/ stabilization of ash from medical waste incineration into geopolymers. Waste Manage. 34, 1823-1828.

Vaou, V., Panias, D., 2010. Thermal insulating foamy geopolymers from perlite Miner. Eng. 23, 1146-1151.

Wagner, T.P., 2011. Compact fluorescent lights and the impact of convenience and knowledge on recycling rates. Waste Manage. 31, 1300-1306.
Zhang, M., El-Korchi, T., Zhang, G., Liang, J., Tao, M., 2014. Synthesis factors affecting mechanical properties, microstructure, and chemical composition of red mudfly ash based geopolymers. Fuel 134, 315-325.

Zhang, Z., Wang, H., Provis, J.L., Bullen, F., Reid, A., Zhu, Y., 2012. Quantitative kinetic and structural analysis of geopolymers. Part 1 . The activation of metakaolin with sodium hydroxide. Thermochim. Acta 539, 23-33. 